\title{
The illusion of science in comparative cognition
}

\author{
2 October 2019 \\ Benjamin G. Farrar ${ }^{1,2}$ and Ljerka Ostojić $\dot{c}^{1,2}$ \\ ${ }^{1}$ Department of Psychology, University of Cambridge, Cambridge, UK \\ ${ }^{2}$ Institute for Globally Distributed Open Research and Education (IGDORE) \\ Corresponding authors: Benjamin G. Farrar, bgf22@cam.ac.uk \\ Ljerka Ostojić, ljerkaost@gmail.com
}

\begin{abstract}
A prominent vein of comparative cognition research asks which cognitive abilities may be ascribed to different species. Here, we argue that the current structure of comparative cognition makes it near impossible to evaluate the accuracy of many of the claims produced by the field's empirical research. We base this argument on six observations: i) the field is biased towards confirming more exceptional abilities in animals, ii) a likely high rate of false positive discovery, iii) the persistence of the bias towards more exceptional abilities, even in the presence of strong methodological criticism, iv) the absence of a formal method to assess evidence of absence of a cognitive ability, v) the ambiguity in definitions used to make claims, and vi) the small size of the research field. We then highlight how the widespread methodological and conceptual criticism in the comparative cognition literature does not facilitate scientific progress, rather it can impede it by creating an illusion of scientific rigour. Finally, we call for a reform of our research field that draws on recent developments in related fields and the Open Science movement.
\end{abstract}




\section{The context of this paper}

It has been pointed out to us that the reader may benefit from knowing how we came about to write this paper. That they may find it easier to think through and be open to the arguments of this paper if we shared a bit of the personal story behind it. This paper represents the result of a long process that led us to question and re-examine scientific research in a much more profound way than ever before, very much including our own work.

In June 2018, within a few weeks we went from being a first year PhD student interested in theory of mind and a Research Associate planning their research programme to apply for a junior research group to being two scientists who have firmly decided that we could not continue conducting research in the same way as before. Taking the time and space to allow ourselves to dig into issues brought forward by others in various different disciplines meant that we also had to work through how these affected our own beliefs and views of science, our own empirical work, our own behaviour and decisions, as well as our own education, teaching, and mentoring. This process was at times very uncomfortable, at times very exciting, at times we thought we were plainly wrong or were misunderstanding the implications of our arguments. We sought support from others who seem to have gone through similar processes, and this support proved invaluable.

Now, fifteen months later, we have finally been able to put these thoughts to paper - the result of which is in front of you. When we are engrossed in a research programme, most of our time and effort is taken up by it. Taking a step back to evaluate the framework itself can be difficult. We hope that this paper may aid others in doing so if and when they decide to take that step. 


\section{Introduction}

In "The Snark Was a Boojum", Beach (1950) lamented the limited focus of comparative psychology on learning mechanisms in the lab rat. In an analogy based on Lewis Carrol's poem "The hunting of the Snark", Beach contended that in hunting for the delicious Snark, Animal Behaviour, Comparative Psychologists instead found a deadly Boojum, the albino rat; as a result, the Comparative Psychologist faded away.

Nearly 70 years on, the situation is markedly different; our research field has overcome this overspecialization and boasts a wide range of research questions across many different species (Beran, Parrish, Perdue, \& Washburn, 2014; Shettleworth, 2009; Vonk, 2016). One prominent vein of this research has been structured around a subfield asking which cognitive abilities we might attribute to different species, which we will refer to as 'phenomenon-based comparative cognition'. This is the field in which we have worked for a varying number of years. In phenomenon-based comparative cognition, researchers pose questions as diverse as whether animals possess knowledge about physical principles, whether they can interact with other individuals by representing their mental states, and whether they can recognise themselves when presented with their own image. Over the past 40 years or so, the number of claims of so-called "higher", more exceptional, cognitive processes in animals that has resulted from this research seems to be rising. However, because of the diversity of questions posed and the number of species investigated, only a few researchers work on the same problems in the same species. And hidden in Beach's original article was a caution about the difficulty of maintaining scientific rigour with such a structure:

"There are many important advantages to be gained when many independent research workers attack similar problems using the same kinds of organisms... [it is] possible to check the accuracy of the findings, to accelerate the acquisition of new data, and to formulate more valid and general conclusions than could have been derived if each worker dealt with a different species." (Beach, 1950)

Today, the Snark may no longer be a Boojum, but are we really doing any better? Engaging with this question has led us to the conclusion that the current structure of phenomenon-based comparative cognition produces many inferences about animal cognition that may be inaccurate, and, more critically, for many claims, it is not even possible to evaluate the accuracy of these inferences.

Research in comparative cognition is biased in the direction towards confirming more exceptional cognitive abilities in the study animals (what we will hereafter refer to as 'directional bias'), and the research is being performed in a manner that is likely to produce many false positive findings. Rather than exposing our theories to severe and risky tests, phenomenon-based comparative cognition currently proceeds by engaging in a confirmatory sweep for positive evidence in order to make the cognitive abilities of study species more exceptional, more publishable and more citable. However, during this sweep we perform many 'rituals' that may give the illusion of a scientifically rigorous process: We generate hypotheses, construct detailed study plans, perform statistical analyses and embrace a culture of methodological and conceptual criticism. But despite these procedures, factors commonly regarded as extra-scientific, such as researchers' interactions, social expectations and chance decisions might have a larger influence on the results that we produce than the cognitive abilities of the animals themselves. In this system, it might not be possible to answer the very questions that interest us, but the illusion of successfully doing so prevents us from acknowledging, studying, or changing this situation. 
"If there are fundamental problems with the way the data have been collected, then no amount of clever methods can eliminate these biases" (Spiegelhalter, 2019, pg. 247)

"...it is when researchers try to test [conjectures about hard to reach concepts] with sciency sounding methods that the project becomes pseudosciency" (Mayo, 2018, pg. 107)

\section{The argument}

We argue that the current structure of phenomenon-based comparative cognition makes it near impossible to evaluate the accuracy of many of the claims produced by the field's empirical research, and this argument is based on the following observations:

1) Phenomenon-based comparative cognition uses confirmatory research methods that are directionally biased

2) In combination with a publication bias and a likely high rate of false discoveries, this bias suggests our literature contains many false positive findings

3) This directional bias persists even with strong methodological criticism, and when researchers explicitly consider alternative explanations for the phenomena studied

4) No formal method exists for generating and assessing theory-disconfirming evidence that could counter the biased positive evidence

5) Ambiguity in definitions allow us as researchers to flexibly adjust our substantive claims depending on whether we are refuting criticism or selling the results

6) The small size of comparative cognition as a research field perpetuates and reinforces points 1 to 5 .

In making the above argument, we draw from a literature that spans fields, disciplines and time (Beran, 2018; Button et al., 2013; Cohen, 1994; Gigerenzer, 1998a; Greenwald, 1993; Ioannidis, 2005; Kerr, 1998; Latour, 2003; Latour \& Woolgar, 1986; Mayo, 2018; Meehl, 1967; Munafò et al., 2017; Rosenthal, 1979; Smaldino \& McElreath, 2016; Stevens, 2017). Critically, the argument does not apply exclusively to or evenly throughout phenomenon-based comparative cognition. And at many times in the paper, it will be possible to generate counter-examples to the positions held. However, our argument is not that every study or publication will display all of these problems, nor that researchers deliberately engage in biased or questionable research practices; rather it identifies an overarching pattern of the biases that drives many results in phenomenon-based comparative cognition. This pattern threatens to prevent the field as a whole from making progress, and even if 'true' discoveries are made in the meantime, it may not possible to identify them with confidence.

Before explaining and discussing the above argument, first we will define what constitutes phenomenon-based comparative cognition and what we mean by more and less exceptional cognitive abilities and theories.

\section{Phenomenon-based comparative cognition}

Phenomenon-based comparative research primarily focuses on whether or not a particular cognitive ability is present in a particular species or group, and any ancillary questions that arise. Building on a tradition of operationalism, such research typically unfolds by setting a behavioural criterion within an experiment that would be nominally indicative of the cognitive ability in question, for example the what-where-when, or what-where-which, criteria set for episodic-like memory (Clayton \& Dickinson, 
1998; Easton \& Eacott, 2008). Typically, hypothesis tests are used to reject no difference between two or more conditions or groups in the experiment ${ }^{1}$. This procedure is used to support the inference that behaviour $A$ is observed in species $Y$ because they possess cognitive ability $X$. Often, this research aims to confirm the presence of a cognitive ability that is perceived to be more exceptional than previously thought in the study species. By more exceptional abilities, we refer to what others might call higher, complex or sophisticated cognitive abilities, abilities that seem to make the study animals stand out in comparison to other species. In confirming the presence of these abilities, researchers can claim to have discovered something novel or groundbreaking. This procedure leads to research that is on the whole more publishable, more citable and can lead to greater funding opportunities.

\section{Phenomenon-based comparative cognition uses biased confirmatory research methods}

The primary research methods used in comparative cognition research are confirmatory (Gelman, 2014; Meehl, 1967; Rozeboom, 1960). When a researcher rejects the null hypothesis in favour of the alternative hypothesis this leads researchers to confirm the alternative hypothesis and the substantive theory it was derived from, i.e. the theoretical claim that motivated the research. By contrast, when the null hypothesis is not rejected, these null results are often labeled as difficult to interpret and are often not published. This asymmetry allows (well-meaning) comparative cognition researchers to construct hypotheses with the only real possibility of eventually confirming them. In theory, if a researcher wanted to confirm the presence of cognitive ability $X$ in species $Y$, all that is required is to repeatedly test this and publish only the positive, theory-confirming results.

While such confirmatory methods and the selective publication of positive results are pervasive across scientific disciplines (Fanelli, 2010b; Ferguson \& Heene, 2012; Nissen, Magidson, Gross, \& Bergstrom, 2016), the situation in phenomenon-based comparative cognition is biased further because the direction of confirmation is primarily focused on confirming the presence of more and more exceptional cognitive abilities in animals. This directional bias is present before data collection begins, and it can be seen already when researchers design their hypotheses (Klayman \& Ha, 1987; Loehle, 1987; Nickerson, 1998; Wason, 1960, 1968). When designing a study, comparative researchers appear biased toward imagining only behaviour(s) that would be consistent with an animal having the target cognitive ability. Hypotheses tests are then built around this identified behaviour $A$, the nominated indicator of cognitive ability $X$, and an experiment is designed with the following null and alternative hypotheses:

\section{$\mathrm{H}_{0}$ : Does not display behaviour $\mathrm{A}$ \\ $\mathrm{H}_{1}$ : Displays behaviour A}

Then, if $\mathrm{H}_{0}$ can be rejected following the experiment and analysis, researchers proceed to infer $\mathrm{H}_{1}$ and corroborate the substantive claim and cognitive theory motivating it. Conversely, if $\mathrm{H}_{0}$ is not rejected, generally no firm claims are made with respect to the cognitive theory and various alternative hypotheses may be discussed, ranging from less exceptional cognitive theories, to lack of statistical power and failures of the experimental method and/or auxiliary assumptions. There are a vast number of plausible, but untested, post-hoc reasons why a study could have "failed". For example, what if the animals were not paying attention? What if the study design was too insensitive to detect a real effect?

\footnotetext{
${ }^{1}$ Although much of this article is framed in terms of hypothesis tests and frequentist statistics, the same argument applies when other methods, such as model selection and Bayesian statistics are used.
} 
What if the animals were not motivated to engage with the task? When these reasons are considered, it becomes clear that in many phenomenon-based comparative cognition studies, only the positive result counts. Our more exceptional cognitive theories are seldom subjected to risky or severe tests (Mayo, 2018; Meehl, 1990; Popper, 1962). In such a system, the eventual confirmation of more exceptional cognitive abilities in animals is almost inevitable.

\section{False positive literature: Almost anything could be confirmed in comparative cognition, even if it is not true}

By themselves, confirmatory research methods might not lead to a greatly misleading literature, even when the direction of this confirmation is biased. However, when these confirmatory research methods are combined with a high rate of false discovery and a publication bias hiding (at least a large proportion of) negative results from the literature, then the literature can end up containing few identifiably meaningful reports. In this section, we put forward reasons as to why the rate of false discovery is likely high in comparative cognition, such that the results of any given paper might be invalid.

The case that phenomenon-based comparative cognition contains many statistically false positive findings can be made by analogy based on two overlapping observations in related fields:

1) Comparative cognition uses similar research and analysis methods to those used in related fields with a known high number of false positives, as shown by the results of large-scale replication studies

2) Surveys of researchers in related disciplines, namely psychology, ecology and evolution, suggest that analytical practices that increase false positive results are prevalent in the current research climate, a notion reinforced by systematic studies of analysis and reporting practices across the fields

Making the case based on replication studies

In fields in which large-scale replication studies have been conducted, around $60 \%$ of replication studies have returned a significant result in the same direction as the original study (Table 1). While there are several definitions of a successful replication (e.g. Etz \& Vandekerckhove, 2016; Patil, Peng, \& Leek, 2016), replication success appears low specifically in those fields that share similar properties with comparative cognition, such as infant studies: small sample sizes and noisy measurements.

Table 1: Replication rates from large-scale replication efforts in human psychology

\begin{tabular}{|c|c|c|c|c|}
\hline Study & Reference & N & \multicolumn{2}{|c|}{ "Successful" } \\
\hline Open Science Collaboration & $\begin{array}{c}\text { Open Science } \\
\text { Collaboration, } \\
(2015)\end{array}$ & 97 & 36 & 37 \\
\hline Many Labs 1 & $\begin{array}{c}\text { Klein et al., } \\
(2014)\end{array}$ & 13 & 10 & 77 \\
\hline
\end{tabular}




\begin{tabular}{|c|c|c|c|c|}
\hline Many Labs 2 & $\begin{array}{c}\text { Klein et al., } \\
(2018)\end{array}$ & 14 & 28 & 50 \\
\hline Many Labs 3 & $\begin{array}{c}\text { Ebersole et al., } \\
(2016)\end{array}$ & 13 & 3 & 23 \\
\hline Experimental Economics & $\begin{array}{c}\text { Camerer et al., } \\
(2016)\end{array}$ & 18 & 11 & 61 \\
\hline $\begin{array}{c}\text { Social Psychology } \\
\text { Nature/Science }\end{array}$ & $\begin{array}{c}\text { Camerer et al., } \\
(2018)\end{array}$ & 21 & 13 & 62 \\
\hline $\begin{array}{c}\text { Experimental Philosophy } \\
\text { Cova et al., } \\
(2018)\end{array}$ & 37 & 29 & 100 \\
\hline Cognitive Psychology & $\begin{array}{c}\text { Zwaan et al., } \\
(2018)\end{array}$ & 9 & 9 & 78 \\
\hline
\end{tabular}

'Study' refers to the names of the replication project. 'Year' refers to the year of the publication. ' $N$ ' refers to the number of replication attempts. "Successful" refers to replication attempts that were considered to have replicated the original findings. 'Absolute' refers to the absolute number of studies that were considered to have replicated the original findings. '\%' refers to the percentage of studies that were considered to have replicated the original findings.

This replication rate of around $60 \%$ could provide an anchor for estimating replication rates of studies in comparative cognition. However, several factors may limit the generalisability of these large-scale human replication projects to comparative cognition. The types of effects replicated in human projects are markedly different from those studied in comparative cognition. This is because the studies at the centre of the replication initiatives were not a random sample of psychological studies, but often selected for their ease of replication and distribution to many participants. Furthermore, many of the failed replications occurred with studies that used between-subjects designs, contrasting with the within-subjects designs often used in comparative cognition. These within-subject designs might improve replicability as they attempt to remove inter-subject noise from measurements (Smith \& Little, 2018; Stevens, 2017, e.g. this might explain the high replication rate in Cognitive Psychology (Table 1); a field that regularly employs within-subject designs). On the other hand, this benefit might be offset in most comparative cognition studies due to the large noise often inherent with working with behaviours exhibited by animals, the lack of precision of small-sample studies (Gelman \& Carlin, 2014) and the prevalence of single/few trial within-subject design measures.

A further guide for comparative cognition could be phenomenon-based infant cognition studies. In contrast to large-scale adult replication studies, infant cognition studies share many similar design features and constraints with comparative cognition, such as similar research questions, small sample sizes and difficult to control participants. Furthermore, the fields also share the directional bias towards confirming more surprising results. In developmental studies this bias usually manifests itself in attempts to infer the presence of certain cognitive abilities at an earlier and earlier age (Peterson, 2016). Such infant cognition research is currently experiencing an accumulation of failed replications and negative results, for example in infant theory of mind research (Poulin-Dubois et al., 2018). Finally, our expectation that replicability rates will be low in phenomenon-based comparative cognition specifically is reinforced by findings that fundamental effects in animal (and human) learning, such as blocking, may be far less reliable, (robust) and generalisable than is usually assumed (Maes et al. 2016). 
While we cannot produce an accurate estimate the replicability of comparative cognition results from large-scale human replication studies, infant cognition studies or animal learning data, given the shared general method of investigation, we can infer that - if we were to perform similar studies - we should expect that replication rates will be low. The next question is what causes these rates to be low? One popular suggestion is that false positive inflating research methods and analytical practices are a root cause of the current replication issues in psychology (Simmons, Nelson, \& Simonsohn, 2011). This cause is further exacerbated in a system with a strong selection for positive results, and where many studies are performed with tests that have low power to detect meaningful effect sizes.

\section{Making the case based on research and analysis practices}

Two methods have been used to quantify the rate of researchers using false positive inflating research and analysis practices: self-report surveys and meta-research projects. Self-report surveys indicate that many researchers report to have used, and suspect that others use, so-called "questionable research practices", which elevate the rate at which positive evidence can be presented (Fiedler \& Schwarz, 2016; Fraser, Parker, Nakagawa, Barnett, \& Fidler, 2018; John, Loewenstein, \& Prelec, 2012). While some of the surveys may have biased the reported results towards higher figures (see Fiedler \& Schwarz, 2016), the evidence from the various surveys shows that there is a non-trivial usage of these practices. The rates of some of these practices can be also be investigated through meta-research projects, an interdisciplinary approach to evaluating methods, reporting, reproducibility and the evaluation and incentives of research (loannidis, 2018; loannidis, Fanelli, Dunne, \& Goodman, 2015). Thus far, meta-research projects have largely corroborated the findings of survey projects (Chuard, Vrtílek, Head, \& Jennions, 2019; Fanelli, 2010a, 2012; Gibbs \& Gibbs, 2015; Head, Holman, Lanfear, Kahn, \& Jennions, 2015; loannidis, 2005; Nieuwenhuis, Forstmann, \& Wagenmakers, 2011; PoulinDubois et al., 2018; Sena, Worp, Bath, Howells, \& Macleod, 2010), and these converge on narratives from other fields, such as ethnographic studies of scientific practice (Latour \& Woolgar, 1986; Peterson, 2016). Many of the research practices identified in these meta-research and survey studies, if not corrected for, increase the likelihood of a statistical hypothesis test yielding a false positive result. Their combined effect can lead to the likelihood of a study returning a significant result to be upwards of 50\%, even when there is no real effect (Simmons et al., 2011).

While there is a developing literature on these questionable research practices in psychology and ecology, the exact prevalence of each practice likely differs in comparative cognition (e.g. see Holman et al., 2016). However, the following examples should make evident that each of us is likely to have encountered these practices in our work in one way or another. For example, sample sizes or stopping rules and exclusion criteria may not be determined before testing begins. Researchers may have multiple looks at the data before deciding when to stop, or alternatively may stop collection once a positive result is achieved. Researchers may record several different dependent variables, and selectively report or interpret those that 'worked' (John et al., 2012). In the process of exploring the results, researchers may find associations that were not predicted and report these as the result of confirmatory tests (Kerr, 1998). Alternatively, they begin testing with under-specified hypotheses that could be answered through a vast number of justifiable, and often equally valid, analytical pipelines (Silberzahn et al., 2017; Steegen, Tuerlinckx, Gelman, \& Vanpaemel, 2016; van der Vaart \& Hemelrijk, 2014, p346). However, only a subset of these pipelines might contain statistically significant p-values. Researchers may analyse subsets of data, or data from particular trials, and may be biased in excluding certain participants, either knowingly or unknowingly (Holman et al., 2016). Even after these tests have been conducted, researchers may further make errors in the interpretation of the results of their statistical tests, for example by concluding that there is a statistical difference between a 
group/condition that exhibits a significant effect (e.g. $p=.049)$ and a group/condition that does not (e.g. $p=.051$ ), without directly testing for a difference between these two groups (Gelman \& Stern, 2006; Nieuwenhuis et al., 2011). An important issue in that regard is that many of these practices have become normalised to such an extent that researchers employing them likely do not know that they are increasing the chances of false positive results.

\section{Interim Summary: "Do we not try to combat these issues?"}

Thus far this paper has laid out several reasons why phenomenon-based comparative cognition research may struggle to produce inferences about animal cognition that we can readily evaluate how accurate they are. . It has claimed that phenomenon-based comparative cognition uses confirmatory research methods that are biased towards confirming the presence of more exceptional cognitive abilities in animals. When the directionally biased confirmatory methods are combined with false positive inflating research practices and publication bias, the literature can become filled with misleading results, and this is likely the situation in phenomenon-based comparative cognition.

While reading the above, the reader may have felt that this picture is too negative and one-sided. Perhaps the strong methodological criticism that is present throughout our literature, which we have not yet touched upon, may combat some of the issues. This criticism is the foundation of incremental and cumulative science, and supposedly leads us to design progressively better and more valid tests. It has even been suggested that such criticism produces an under-attribution bias, namely that researchers are biased away from confirming more exceptional abilities (Mikhalevich, 2015). In the following sections we will suggest that rather than being a feature of a rigorous scientific process, the prevalence of so much methodological criticism can be viewed as a symptom of a poorly functioning scientific system. Specifically, we will address the following two issues. First, we will illustrate why the directional bias towards more exceptional abilities persists even when researchers explicitly consider less exceptional theories, and how we are unable to formally assess the evidence of absence of an exceptional cognitive ability. Secondly, we will discuss how in light of the distance between the substantive claims and the statistical hypotheses in our field, this methodological criticism can inhibit our scientific progress.

\section{The directional bias persists even when alternative theories are considered}

We have argued that the presence of the directional bias in phenomenon-based comparative cognition inevitably leads to the confirmation of more exceptional abilities in animals. Surely, then, considering alternative theories in our research could attempt to ameliorate this concern? This could be possible if studies directly compared competing hypotheses, with each making risky predictions (Platt, 1964). However, despite these so-called strong inference strategies being feasible in comparative cognition ${ }^{2}$, this method is remarkably infrequent. Rather, less exceptional cognitive theories are usually considered after experiments have been performed. This approach does not alleviate the directional bias towards confirming more exceptional theories, because postexperimental evidence in favour of less exceptional cognitive theories ${ }^{3}$ is often not used to make a

\footnotetext{
${ }^{2}$ Albeit theoretically and practically more demanding and time consuming

${ }^{3}$ And often this is not evidence in favour of the less exceptional ability over the more exceptional ability, rather solely demonstrating the evidence is also compatible with the less exceptional ability.
} 
generalizable claim regarding the substantive theory, but rather serves to invalidate the actual experiment as a test of more exceptional theories. This problem is exacerbated by the fact that, in comparative cognition, test development and test use are not separated. Thus, the validity of a measure is routinely discussed after the measure has already been applied to test a substantive claim and is less easily disentangled from the results that have already been obtained.

As an example, consider a recent study claimed that ravens exhibit a domain-general ability of planning by reporting flexible planning in both tool-use and bartering (Kabadayi \& Osvath, 2017). While the original authors' claim suggests a generalizable discovery about raven cognition, it has been highlighted that the results are also consistent with the ravens having used domain-general associative learning processes (Lind, 2018; Redshaw, Taylor, \& Suddendorf, 2017). However, in contrast to the original interpretation, the claim of the associative learning explanation makes no such attempt to make general inferences about raven cognition. Instead, the claim is tied to the validity of the behavioural task at hand, for example Redshaw et al. state:

"Thus, a lean alternative hypothesis is that the learned reward associations simply made the functional items more attractive than the distractors." (Redshaw et al., 2017, pg. 821)

This form of criticism can prevent us from prematurely concluding that ravens can flexibly plan for the future. However, it cannot prevent the only general conclusions that can be derived from a sequence of studies like this, even when we have considered the alternative, less exceptional cognitive theories, from being that the animals do possess the more exceptional cognitive ability.

This is not to say that strong inference strategies are not possible, just that they are rarely successfully used $^{4}$. This contrasts with the vast swathes of methodological criticism in the field (e.g. Byrne, 2002; Guez \& Audley, 2013; Hennefield, Hwang, Weston, \& Povinelli, 2018; Heyes, 2015; Heyes, 1993; Kohda et al., 2019; Penn \& Povinelli, 2007; Redshaw et al., 2017; Silva, Page, \& Silva, 2005; Silva, Ten Hope, \& Tucker, 2014; van der Vaart, Verbrugge, \& Hemelrijk, 2012), which are examples of the postexperimental consideration of less exceptional explanations we described above. On the whole, if a comparative cognition study confirms a more exceptional theory, it is taken to say something general about that animal's abilities. In contrast, if a study confirms a less exceptional theory, the study itself ceases to be considered a valid test of the more exceptional theory, and as such the more exceptional theory is not and cannot be disconfirmed. Consequently, rather than being a hallmark of a rigorous scientific method, the frequent methodological criticism in comparative cognition can be a symptom of a poorly functioning system.

\section{The inability to formally assess evidence of absence}

A related problem is that, while there exists a formal method of confirming that a species does have a certain cognitive ability, there is no formal method of assessing evidence that a species does not have the ability. This structure reinforces the directional bias in research programmes - not only do researchers not attempt to generate theory-disconfirming evidence, there does not actually exist an established framework for them to do so.

Currently, researchers may arrive at the conclusion that an animal likely does not have a certain cognitive trait either based on the continued absence of evidence of the ability in the literature, or because the results of a single study appear to disconfirm the presence of the ability in that species.

\footnotetext{
${ }^{4}$ Although strong inference strategies are sometimes called for, e.g. Povinelli (1996).
} 
The former method is not sufficient as the relative lack of confirming evidence in the literature is dependent on a host of information unavailable to outside researchers, such as the intensity of research and the amount of unpublished work. On the other hand, there are very few examples of research that satisfactorily disconfirms the presence of a certain ability in animals ${ }^{5}$, possibly because negative results are rarely published, and because there has been no formal method of assessing evidence against more exceptional theories.

Some researchers have, however, attempted to provide evidence disconfirming the presence of more exceptional cognitive abilities in animals. For example, Suddendorf and Collier-Baker (2009) conducted a mirror-mark test in which gibbons did not use a mirror to locate hidden marks above their brow. Crucially, they also provided evidence that if the gibbons were capable of self-recognition, it would have been unlikely that the gibbons would not have used the mirror to locate the marks. They did this by conducting additional tests, demonstrating that the gibbons were strongly motivated to retrieve edible marks from their own bodies and mirror surfaces. From this, Suddendorf and CollierBaker made the reasonable prediction that if the gibbons recognized themselves in the mirror then most of the gibbons would have retrieved the mark from their foreheads. In contrast, 0 of 17 gibbons retrieved the mark.

Although this inference was warranted, it was not formalised. Instead, Suddendorf and Collier-Baker's inference was supported by accepting a null hypothesis, technically a statistical fallacy. However, there is a formal analysis that could have been performed to formally reject the claim that gibbons recognize themselves in the mirror. By ensuring that the gibbons were highly motivated and capable of retrieving the mark, Suddendorf and Collier-Baker had, statistically speaking, demonstrated that only large effect sizes were consistent with the hypothesis that gibbons recognize themselves in the mirror. That is, the mirror-self recognition hypothesis would have predicted that if they were capable of self-recognition most (e.g. >13) gibbons would have passed the test. The established effect size, 0 out of 17, appears to be incompatible with this assumption. In order to provide statistical evidence against the mirrorself recognition theory the researchers could have performed an equivalence test (Lakens, 2017; Meehl, 1967), allowing them to reject the possibility that the effect size was large enough to be consistent with the mirror-self recognition theory. Such a procedure is not specific to frequentist statistics, and quantifying evidence against the null hypothesis is highlighted as a benefit of some Bayesian statistics (Mulder \& Wagenmakers, 2016). However, researchers should not simply select a statistical procedure capable of returning results that ostensibly disconfirm their substantive claims. Rather, they should adopt a statistical mindset when developing their research ideas and designs, which can then be formalised by appropriate procedures (Gigerenzer, 1998b). However, without such a step-change in statistical thinking, adopting these procedures will likely be ineffectual or even counter-productive. From a practical point of view, it is important to acknowledge that these changes will likely mean that the research will require (even) more time to perform than a typical comparative cognition study.

\section{Definitional ambiguity and the selling of results}

While misleading statistical inferences can be made from the statistics we perform, inappropriate theory confirmation can also occur during the step of moving from the results of these statistical test

\footnotetext{
${ }^{5}$ And, just like the confirmation of abilities this should require converging evidence from many studies.
} 
to substantive claim. Even if a true positive statistical result is obtained, this does not mean that the substantive claim made by the researchers is true.

When researchers confirm a substantive claim based on a statistical test, this assumes that the statistical hypothesis is a direct and valid test of the substantive theory (Duhem, 1976; Meehl, 1990). However, in phenomenon-based comparative cognition there is usually a large distance between the statistical and substantive hypotheses. It is this distance that is the locus of most methodological criticism in our field which, as we saw above, primarily addresses the validity of the test in question. Insofar as phenomenon-based comparative cognition attempts to test for human-like cognitive capacities in animals (Heyes, 2019), this distance will always be present (Hempel, 1958; Hennefield et al., 2018).

Part of the issue stems from the inherent ambiguity in the verbal hypotheses and definitions that are derived from theory. Across psychology, such verbal models are open to many available and justifiable interpretations (Smaldino, 2016, 2017), and the disagreements that arise from this are common in phenomenon-based comparative cognition (Heyes, 2019). This flexibility afforded by underspecified definitions allows us to produce results that 'cognition optimists' would perceive as novel and groundbreaking, whilst 'cognition pessimists' can equally well use the same results to invalidate the test and/or discuss the lack of evidence for the exceptional theory. Perhaps more paradoxically, definitional ambiguity also allows the same researchers to flexibly adjust their substantive claims depending on whether they are refuting criticism or selling the results.

For example, as Penn and Povinelli (2007) highlight, Dally, Emery and Clayton (2006) "acknowledge, that scrub jays' ability to keep track of which competitors have observed which cache sites 'need not require a humanlike 'theory of mind' in terms of unobservable mental states". However, their title, "Food-caching western scrub-jays keep track of who was watching when", lends itself to more exceptional cognitive interpretations for those who want it, and it is this more exceptional claim that forms the basis of later claims of the potential for higher cognitive abilities in corvids (Clayton, Dally, \& Emery, 2007). Another example comes from Ostojić, Shaw, Cheke, \& Clayton (2013). While the authors of this study believe that the results of this study present a "crucial first step in demonstrating state-attribution" and mean that "Eurasian jays' food-sharing behavior represents a useful paradigm within which to investigate whether these birds, and more generally nonhuman animals, might be capable of desire-attribution" (p. 4127), the claims of the study do lend themselves to be reported as evidence for state-attribution (e.g. Keefner 2016).

Thus, even when true positive statistical results are obtained, confirmations of more exceptional cognitive theories can be misleading. This is because the language used to describe the results can lend them to more exceptional interpretations, without this being warranted. At the same time, the results themselves are protected from criticism, as researchers can point to the lean interpretation of their hypothesis to refute claims of over-interpretation. Consequently, our methodological criticism helps maintain an illusion of scientific rigour, while at the same time it also stifles our scientific progress.

"It is impossible to say that technical literature always errs on the side of caution; it also errs on the side of audacity; or rather it does not err, it zigzags through obstacles" (Latour, 2003, pg. 55)

\section{Why is being a small research field a problem?}


As stated earlier, many of the issues discussed in this paper are not exclusive to phenomenon-based comparative cognition and have in some form or other been discussed by different researchers in different fields. However, the extent of these issues appears to be very severe in comparative cognition. One of the reasons for this is the field's small size. Beach (1950) was clear that where many researchers and groups work on the same problems it becomes "possible to check the accuracy of the findings, to accelerate the acquisition of new data, and to formulate more valid and general conclusions than could have been derived if each worker dealt with a different species." However, while phenomenon-based comparative cognition is diverse in terms of the number of species examined and types of questions asked (Beran et al., 2014; Shettleworth, 2009), only a few researchers reside within each species and question (e.g. Heyes, 2015). This prevents us both from independently replicating others' work, and from being able to detect when research programmes might be going down blind alleys.

Researchers can frequently change topics in response to diminishing returns in their current research field which is an issue if, as this paper claims, normalised research methods can readily and reliably produce false positive results. Currently the decision to study a cognitive capacity in animals can be synonymous with the decision to accept the presence of these abilities in the animals in question. The actual research acts more as a negotiation as to how this conclusion will be reached, not whether it will be reached. In response to diminishing returns in one area, for example due to exhausting easyto-perform experiments, the very same research methods can be refocused onto a new topic, or a new species, and produce a wad of new positive reports. During this process, the field has the illusion of productivity as lots of "discoveries" are published, however these findings are rarely verified. This process does not just occur across research questions and species, but also methods. At a time when technologies are being adapted for use in animal cognition research, for example $\mathrm{fMRI}$ in dogs (Andics et al., 2016), or eye-tracking in apes (Krupenye, Kano, Hirata, Call, \& Tomasello, 2016), a large methodspace Is being opened to which the field's confirmatory methods can be applied.

A final issue with comparative cognition having a small number of researchers working on certain questions in certain species is that these researchers must be responsible for generating data that can both confirm or disconfirm theories. Often, an external skeptic can only attempt to disconfirm theories empirically with the consent of the laboratory that proposed the theory. There is a clear asymmetry here: skeptics often require consent and collaboration to severely test claims, whereas researchers can readily produce theory-confirming data without the consent of or collaboration with a skeptic.

\section{Reforming the field}

Comparative cognition is yet to have a 'crisis of confidence' comparable to that in other research fields (Baker, 2016), however it displays all the hallmarks of a science that could - if resources were focused on these questions - soon be thrust into a replication crisis, a measurement crisis, or a theory crisis. The latter two are terms that are slowly finding their place in the growing discussions within psychology: replicability issues are intertwined with more fundamental questions regarding measurement theory and theory development (Flake \& Fried, 2019; Frank et al., 2017; Klein, 2014; Muthukrishna \& Henrich, 2019; Parsons, 2018; Świątkowski \& Dompnier, 2017). While these issues may not be new, in the day-to-day job of conducing empirical research they are largely ignored.

However, many initiatives have been proposed that are geared towards improving the replicability and reproducibility of research (Asendorpf et al., 2013; Beran, 2018; C. D. Chambers, 2013; Munafò et 
al., 2017; Open Science Collaboration, 2015; Stevens, 2017). These recommendations have the potential to reduce publication bias and false positive inflating research practices. The benefits of these 'open science' principles and tools for comparative cognition have been acknowledged in recently published commentaries by Michael Beran (Beran, 2018) and Jeffrey Stevens (Stevens, 2017). Importantly, however, we believe that if comparative cognition is serious about taking this opportunity, then these changes should not be a matter of convenience, but a matter of a necessary reform ${ }^{6}$.

However, increasing the transparency and improving replicability and reproducibility of research will not be sufficient to produce an effective research system. If fixing the reproducibility issues in science really does represent a 'credibility revolution' (Vazire, 2018), it must co-occur with an increased focus on methods and theory, both within each discipline but also with an overarching and general assessment of scientific processes. In comparative cognition, we should explore ways of reducing the directional biases in research programmes and assess how we could generate theory-disconfirming evidence as well as we produce theory-confirming evidence. At the very least, research programmes in phenomenon-based comparative cognition should be able to show that the conclusions of their publications will differ depending on whether the study species does or does not have the cognitive abilities in question.

Comparative cognition needs also to re-ignite interest in its measures, because the development of behavioural tests in our field has progressed largely independently of discussions and developments in psychometrics and measurement theory. As a first step, we may benefit from a separation of test development and test use in investigating a substantive claim.

The final consequence of the argument presented here is that many prevailing beliefs about the degree of confirmation of exceptional cognitive abilities in animals may be unwarranted. There is a vast amount of knowledge sealed in the published literature, which can only begin to be unlocked by evaluating the reliability of the research performed. Over the next decades we may have to re-open facts that were considered closed, and we should begin to evaluate whether the process by which these facts were constructed is an effective one. As well as asking whether animals have certain cognitive abilities, comparative cognition should at the same time focus on whether its scientific method is capable of answering these questions efficaciously. Currently, comparative cognition uses sciency-sounding methods, but whether these methods work is a scientific question in itself.

"If we ignore the warning signs now, then in a hundred years or less, psychology may be regarded as one in a long line of quaint scholarly indulgencies, much as we now regard alchemy or phrenology" (C. Chambers, 2017).

We share this worry, although at the same time we recognise the above may well be an inevitable part of science. Perhaps more than this we worry that the time when the current research will be viewed as 'a quaint scholarly indulgency' will be much later than necessary. As a (comparative cognition) researcher, every single one of us has an ethical responsibility now to not ignore the warning signs.

\footnotetext{
${ }^{6}$ This is not to say that all tools that have been developed to date will be applicable to every research area and at all times, nor is it to say that these tools should be used 'blindly' or as a box-ticking exercise. The value of the 'open science' principles and tools will be greatest when they also foster critical evaluation of one's own research procedures and methods.
} 


\section{Acknowledgements}

We thank Katharina Brecht, Rachel Crosby and Edward Legg for extensive discussions, input and comments on different versions of this manuscript. We thank Corina Logan, Lucy Cheke, Rachael Shaw, Mike Beran, Jennifer Vonk, Ivan Flis, Chris Chambers, Alice Bridges, Krešimir Đurđević, Mike Mendl, Claudia Wascher, Manuel Bohn and Chris Krupenye for multiple discussions about these topics. We thank Claudio Tennie, Chris Chambers, Hannah Fraser, Nicky Clayton, and Mike Beran for feedback on an earlier version of this manuscript. We would like to thank Nicky Clayton for encouraging us to pursue this work. Finally, we would like to thank all people we have discussed these topics with over the last year.

\section{Funding}

BGF received support for this work from a BBSRC DTP studentship. 


\section{References}

Andics, A., Gábor, A., Gácsi, M., Faragó, T., Szabó, D., \& Miklósi, Á. (2016). Neural mechanisms for lexical processing in dogs. Science, 353(6303), 1030-1032.

https://doi.org/10.1126/science.aaf3777

Asendorpf, J. B., Conner, M., Fruyt, F. D., Houwer, J. D., Denissen, J. J. A., Fiedler, K., ... Wicherts, J. M. (2013). Recommendations for Increasing Replicability in Psychology. European Journal of Personality, 27(2), 108-119. https://doi.org/10.1002/per.1919

Baker, M. (2016). 1,500 scientists lift the lid on reproducibility. Nature News, 533(7604), 452. https://doi.org/10.1038/533452a

Beach, F. A. (1950). The Snark was a Boojum. American Psychologist, 5(4), 115-124. https://doi.org/10.1037/h0056510

Beran, M. J. (2018). Replication and Pre-Registration in Comparative Psychology. Retrieved from https://escholarship.org/uc/item/59f4z2nd

Beran, M. J., Parrish, A. E., Perdue, B. M., \& Washburn, D. A. (2014). Comparative Cognition: Past, Present, and Future. International Journal of Comparative Psychology / ISCP ; Sponsored by the International Society for Comparative Psychology and the University of Calabria, 27(1), $3-30$.

Button, K. S., A loannidis, J. P., Mokrysz, C., Nosek, B. A., Flint, J., J Robinson, E. S., \& Munafò, M. R. (2013). Power failure: Why small sample size undermines the reliability of neuroscience. Nature Publishing Group, 14. https://doi.org/10.1038/nrn3475

Byrne, R. W. (2002). Imitation of novel complex actions: What does the evidence from animals mean? In Advances in the Study of Behavior (Vol. 31, pp. 77-105). https://doi.org/10.1016/S0065-3454(02)80006-7

Camerer, C. F., Dreber, A., Forsell, E., Ho, T.-H., Huber, J., Johannesson, M., ... Wu, H. (2016). Evaluating replicability of laboratory experiments in economics. Science, 351(6280), 14331436. https://doi.org/10.1126/science.aaf0918 
Camerer, C. F., Dreber, A., Holzmeister, F., Ho, T.-H., Huber, J., Johannesson, M., ... Wu, H. (2018). Evaluating the replicability of social science experiments in Nature and Science between 2010 and 2015. Nature Human Behaviour, 2(9), 637. https://doi.org/10.1038/s41562-0180399-z

Chambers, C. (2017). The seven deadly sins of psychology: A manifesto for reforming the culture of scientific practice / Chris Chambers. Princeton: Princeton University Press.

Chambers, C. D. (2013). Registered Reports: A new publishing initiative at Cortex. Cortex, 49(3), 609610. https://doi.org/10.1016/j.cortex.2012.12.016

Chuard, P. J. C., Vrtílek, M., Head, M. L., \& Jennions, M. D. (2019). Evidence that nonsignificant results are sometimes preferred: Reverse P-hacking or selective reporting? PLOS Biology, 17(1), e3000127. https://doi.org/10.1371/journal.pbio.3000127

Clayton, N. S., Dally, J. M., \& Emery, N. J. (2007). Social cognition by food-caching corvids. The western scrub-jay as a natural psychologist. Philosophical Transactions of the Royal Society of London. Series B, Biological Sciences, 362(1480), 507-522. https://doi.org/10.1098/rstb.2006.1992

Clayton, N. S., \& Dickinson, A. (1998). Episodic-like memory during cache recovery by scrub jays. Nature, 395(6699), 272-274. https://doi.org/10.1038/26216

Cohen, J. (1994). The earth is round ( $p<.05)$. American Psychologist, 49(12), 997-1003. https://doi.org/10.1037/0003-066X.49.12.997

Cova, F., Strickland, B., Abatista, A., Allard, A., Andow, J., Attie, M., ... Zhou, X. (2018). Estimating the Reproducibility of Experimental Philosophy. Review of Philosophy and Psychology. https://doi.org/10.1007/s13164-018-0400-9

Dally, J. M., Emery, N. J., \& Clayton, N. S. (2006). Food-caching western scrub-jays keep track of who was watching when. Science (New York, N.Y.), 312(5780), 1662-1665. https://doi.org/10.1126/science.1126539 
Duhem, P. (1976). Physical Theory and Experiment. In S. G. Harding (Ed.), Can Theories be Refuted? (pp. 1-40). https://doi.org/10.1007/978-94-010-1863-0_1

Easton, A., \& Eacott, M. J. (2008). A new working definition of episodic memory: Replacing "when" with "which." In E. Dere, A. Easton, L. Nadel, \& J. P. Huston (Eds.), Handbook of Behavioral Neuroscience (pp. 185-196). https://doi.org/10.1016/S1569-7339(08)00211-7

Ebersole, C. R., Atherton, O. E., Belanger, A. L., Skulborstad, H. M., Allen, J. M., Banks, J. B., ... Nosek, B. A. (2016). Many Labs 3: Evaluating participant pool quality across the academic semester via replication. Journal of Experimental Social Psychology, 67, 68-82. https://doi.org/10.1016/j.jesp.2015.10.012

Etz, A., \& Vandekerckhove, J. (2016). A Bayesian Perspective on the Reproducibility Project: Psychology. PLOS ONE, 11(2), e0149794. https://doi.org/10.1371/journal.pone.0149794 Fanelli, D. (2010a). Do Pressures to Publish Increase Scientists' Bias? An Empirical Support from US States Data. PLOS ONE, 5(4), e10271. https://doi.org/10.1371/journal.pone.0010271 Fanelli, D. (2010b). "Positive” Results Increase Down the Hierarchy of the Sciences. PLOS ONE, 5(4), e10068. https://doi.org/10.1371/journal.pone.0010068

Fanelli, D. (2012). Negative results are disappearing from most disciplines and countries. Scientometrics, 90(3), 891-904. https://doi.org/10.1007/s11192-011-0494-7

Ferguson, C. J., \& Heene, M. (2012). A Vast Graveyard of Undead Theories: Publication Bias and Psychological Science's Aversion to the Null. Perspectives on Psychological Science, 7(6), 555-561. https://doi.org/10.1177/1745691612459059

Fiedler, K., \& Schwarz, N. (2016). Questionable Research Practices Revisited. Social Psychological and Personality Science, 7(1), 45-52. https://doi.org/10.1177/1948550615612150

Flake, J. K., \& Fried, E. I. (2019). Measurement Schmeasurement: Questionable Measurement Practices and How to Avoid Them [Preprint]. https://doi.org/10.31234/osf.io/hs7wm 
Frank, M. C., Bergelson, E., Bergmann, C., Cristia, A., Floccia, C., Gervain, J., ... Yurovsky, D. (2017). A Collaborative Approach to Infant Research: Promoting Reproducibility, Best Practices, and Theory-Building. Infancy, 22(4), 421-435. https://doi.org/10.1111/infa.12182

Fraser, H., Parker, T., Nakagawa, S., Barnett, A., \& Fidler, F. (2018). Questionable research practices in ecology and evolution. PLOS ONE, 13(7), e0200303. https://doi.org/10.1371/journal.pone.0200303

Gelman, A. (2014, September 5). Confirmationist and falsificationist paradigms of science. Retrieved August 12, 2019, from Statistical Modeling, Causal Inference, and Social Science website: https://statmodeling.stat.columbia.edu/2014/09/05/confirmationist-falsificationistparadigms-science/

Gelman, A., \& Carlin, J. (2014). Beyond Power Calculations. Perspectives on Psychological Science, 9(6), 641-651. https://doi.org/10.1177/1745691614551642

Gelman, A., \& Stern, H. (2006). The Difference Between "Significant" and "Not Significant" is not Itself Statistically Significant. The American Statistician, 60(4), 328-331. https://doi.org/10.1198/000313006X152649

Gibbs, N. M., \& Gibbs, S. V. (2015). Misuse of 'trend' to describe 'almost significant' differences in anaesthesia research. BJA: British Journal of Anaesthesia, 115(3), 337-339. https://doi.org/10.1093/bja/aev149

Gigerenzer, G. (1998a). Surrogates for theories. Theory \& Psychology, 8(2), 195-204. https://doi.org/10.1177/0959354398082006

Gigerenzer, G. (1998b). We need statistical thinking, not statistical rituals. Behavioral and Brain Sciences, 21(2), 199-200. https://doi.org/10.1017/S0140525X98281167

Greenwald, A. G. (1993). Consequences of prejudice against the null hypothesis. Hillsdale, NJ, US: Lawrence Erlbaum Associates, Inc.

Guez, D., \& Audley, C. (2013). Transitive or Not: A Critical Appraisal of Transitive Inference in Animals. Ethology, 119(9), 703-726. https://doi.org/10.1111/eth.12124 
Head, M. L., Holman, L., Lanfear, R., Kahn, A. T., \& Jennions, M. D. (2015). The extent and consequences of p-hacking in science. PLoS Biology, 13(3), e1002106. https://doi.org/10.1371/journal.pbio.1002106

Hempel, C. G. (1958). The theoretician's dilemma: A study in the logic of theory construction. Retrieved from http://conservancy.umn.edu/handle/11299/184621

Hennefield, L., Hwang, H. G., Weston, S. J., \& Povinelli, D. J. (2018). Meta-analytic techniques reveal that corvid causal reasoning in the Aesop's Fable paradigm is driven by trial-and-error learning. Animal Cognition, 1-14. https://doi.org/10.1007/s10071-018-1206-y

Heyes, C. (2015). Animal mindreading: What's the problem? Psychonomic Bulletin \& Review, 22(2), 313-327. https://doi.org/10.3758/s13423-014-0704-4

Heyes, C. (2019). What is cognition? Current Biology, 29(13), R608-R615. https://doi.org/10.1016/j.cub.2019.05.044

Heyes, C. M. (1993). Anecdotes, training, trapping and triangulating: Do animals attribute mental states? Animal Behaviour, 46(1), 177-188. https://doi.org/10.1006/anbe.1993.1173

Holman, C., Piper, S. K., Grittner, U., Diamantaras, A. A., Kimmelman, J., Siegerink, B., \& Dirnagl, U. (2016). Where Have All the Rodents Gone? The Effects of Attrition in Experimental Research on Cancer and Stroke. PLOS Biology, 14(1), e1002331.

https://doi.org/10.1371/journal.pbio.1002331

Ioannidis, J. P. A. (2005). Why Most Published Research Findings Are False. PLoS Medicine, 2(8), e124. https://doi.org/10.1371/journal.pmed.0020124

Ioannidis, J. P. A. (2018). Meta-research: Why research on research matters. PLOS Biology, 16(3), e2005468. https://doi.org/10.1371/journal.pbio.2005468

Ioannidis, J. P. A., Fanelli, D., Dunne, D. D., \& Goodman, S. N. (2015). Meta-research: Evaluation and Improvement of Research Methods and Practices. PLOS Biology, 13(10), e1002264. https://doi.org/10.1371/journal.pbio.1002264 
John, L. K., Loewenstein, G., \& Prelec, D. (2012). Measuring the Prevalence of Questionable Research Practices With Incentives for Truth Telling. Psychological Science, 23(5), 524-532. https://doi.org/10.1177/0956797611430953

Kabadayi, C., \& Osvath, M. (2017). Ravens parallel great apes in flexible planning for tool-use and bartering. Science, 357(6347), 202-204. https://doi.org/10.1126/science.aam8138

Keefner, A. (2016). Corvids infer the mental states of conspecifics. Biology \& Philosophy, 31(2), 267281. https://doi.org/10.1007/s10539-015-9509-8

Kerr, N. L. (1998). HARKing: Hypothesizing after the results are known. Personality and Social Psychology Review: An Official Journal of the Society for Personality and Social Psychology, Inc, 2(3), 196-217. https://doi.org/10.1207/s15327957pspr0203_4

Klayman, J., \& Ha, Y. (1987). Confirmation, disconfirmation, and information in hypothesis testing. Psychological Review, 94(2), 211-228. https://doi.org/10.1037/0033-295X.94.2.211

Klein, R. A., Ratliff, K. A., Vianello, M., Adams, R. B., Bahník, Š., Bernstein, M. J., ... Nosek, B. A. (2014). Investigating Variation in Replicability: A “Many Labs" Replication Project. Social Psychology, 45(3), 142-152. https://doi.org/10.1027/1864-9335/a000178

Klein, R. A., Vianello, M., Hasselman, F., Adams, B. G., Adams, R. B., Alper, S., ... Nosek, B. A. (2018). Many Labs 2: Investigating Variation in Replicability Across Samples and Settings. Advances in Methods and Practices in Psychological Science, 1(4), 443-490. https://doi.org/10.1177/2515245918810225

Klein, S. B. (2014). What can recent replication failures tell us about the theoretical commitments of psychology? Theory \& Psychology, 24(3), 326-338. https://doi.org/10.1177/0959354314529616

Kohda, M., Hotta, T., Takeyama, T., Awata, S., Tanaka, H., Asai, J., \& Jordan, A. L. (2019). If a fish can pass the mark test, what are the implications for consciousness and self-awareness testing in animals? PLOS Biology, 17(2), e3000021. https://doi.org/10.1371/journal.pbio.3000021 
Krupenye, C., Kano, F., Hirata, S., Call, J., \& Tomasello, M. (2016). Great apes anticipate that other individuals will act according to false beliefs. Science, 354(6308), 110-114. https://doi.org/10.1126/science.aaf8110

Lakens, D. (2017). Equivalence Tests: A Practical Primer for t Tests, Correlations, and Meta-Analyses. Social Psychological and Personality Science, 8(4), 355-362. https://doi.org/10.1177/1948550617697177

Latour, B. (2003). Science in action: How to follow scientists and engineers through society (11. print). Cambridge, Mass: Harvard Univ. Press.

Latour, B., \& Woolgar, S. (1986). Laboratory life: The construction of scientific facts. Princeton, N.J: Princeton University Press.

Lind, J. (2018). What can associative learning do for planning? Royal Society Open Science, 5(11), 180778. https://doi.org/10.1098/rsos.180778

Loehle, C. (1987). Hypothesis Testing in Ecology: Psychological Aspects and the Importance of Theory Maturation. The Quarterly Review of Biology, 62(4), 397-409. https://doi.org/10.1086/415619

Mayo, D. G. (2018). Statistical inference as severe testing: How to get beyond the statistics wars. Cambridge ; New York, NY: Cambridge University Press.

Meehl, P. E. (1967). Theory-Testing in Psychology and Physics: A Methodological Paradox. Philosophy of Science, 34(2), 103-115. Retrieved from JSTOR.

Meehl, P. E. (1990). Why Summaries of Research on Psychological Theories are Often Uninterpretable. Psychological Reports, 66(1), 195-244. https://doi.org/10.2466/pr0.1990.66.1.195

Mikhalevich, I. (2015). Experiment and Animal Minds: Why the Choice of the Null Hypothesis Matters. Philosophy of Science, 82(5), 1059-1069. https://doi.org/10.1086/683440 
Mulder, J., \& Wagenmakers, E.-J. (2016). Editors' introduction to the special issue "Bayes factors for testing hypotheses in psychological research: Practical relevance and new developments." Journal of Mathematical Psychology, 72, 1-5. https://doi.org/10.1016/j.jmp.2016.01.002 Munafò, M. R., Nosek, B. A., Bishop, D. V. M., Button, K. S., Chambers, C. D., Percie du Sert, N., ... loannidis, J. P. A. (2017). A manifesto for reproducible science. Nature Human Behaviour, 1(1), 0021. https://doi.org/10.1038/s41562-016-0021

Muthukrishna, M., \& Henrich, J. (2019). A problem in theory. Nature Human Behaviour, 3(3), 221229. https://doi.org/10.1038/s41562-018-0522-1

Nickerson, R. S. (1998). Confirmation Bias: A Ubiquitous Phenomenon in Many Guises. Review of General Psychology, 2(2), 175-220. https://doi.org/10.1037/1089-2680.2.2.175

Nieuwenhuis, S., Forstmann, B. U., \& Wagenmakers, E.-J. (2011). Erroneous analyses of interactions in neuroscience: A problem of significance. Nature Neuroscience, 14(9), 1105-1107. https://doi.org/10.1038/nn.2886

Nissen, S. B., Magidson, T., Gross, K., \& Bergstrom, C. T. (2016). Publication bias and the canonization of false facts. ELife, 5, e21451. https://doi.org/10.7554/eLife.21451

Open Science Collaboration, O. S. (2015). PSYCHOLOGY. Estimating the reproducibility of psychological science. Science (New York, N.Y.), 349(6251), aac4716. https://doi.org/10.1126/science.aac4716

Ostojić, L., Shaw, R. C., Cheke, L. G., \& Clayton, N. S. (2013). Evidence suggesting that desire-state attribution may govern food sharing in Eurasian jays. Proceedings of the National Academy of Sciences of the United States of America, 110(10), 4123-4128. https://doi.org/10.1073/pnas.1209926110

Parsons, S. (2018). Visualising two approaches to explore reliability-power relationships [Preprint]. https://doi.org/10.31234/osf.io/qh5mf 
Patil, P., Peng, R. D., \& Leek, J. T. (2016). What Should Researchers Expect When They Replicate Studies? A Statistical View of Replicability in Psychological Science. Perspectives on Psychological Science, 11(4), 539-544. https://doi.org/10.1177/1745691616646366

Penn, D. C., \& Povinelli, D. J. (2007). On the lack of evidence that non-human animals possess anything remotely resembling a "theory of mind". Philosophical Transactions of the Royal Society of London. Series B, Biological Sciences, 362(1480), 731-744.

https://doi.org/10.1098/rstb.2006.2023

Peterson, D. (2016). The Baby Factory: Difficult Research Objects, Disciplinary Standards, and the Production of Statistical Significance. Socius, 2, 2378023115625071. https://doi.org/10.1177/2378023115625071

Platt, J. R. (1964). Strong Inference: Certain systematic methods of scientific thinking may produce much more rapid progress than others. Science, 146(3642), 347-353. https://doi.org/10.1126/science.146.3642.347

Popper, K. R. (1962). Conjectures and refutations: The growth of scientific knowledge (4. ed. (rev.), repr). London: Routledge \& Kegan Paul.

Poulin-Dubois, D., Rakoczy, H., Burnside, K., Crivello, C., Dörrenberg, S., Edwards, K., ... Ruffman, T. (2018). Do infants understand false beliefs? We don't know yet - A commentary on Baillargeon, Buttelmann and Southgate's commentary. Cognitive Development, 48, 302-315. https://doi.org/10.1016/j.cogdev.2018.09.005

Povinelli, D. (1996). Chimpanzee theory of mind?: The long road to strong inference. In P. Carruthers \& P. K. Smith (Eds.), Theories of theories of mind (pp. 293-329). https://doi.org/10.1017/СBO9780511597985.019

Redshaw, J., Taylor, A. H., \& Suddendorf, T. (2017). Flexible Planning in Ravens? Trends in Cognitive Sciences, 21(11), 821-822. https://doi.org/10.1016/j.tics.2017.09.001

Rosenthal, R. (1979). The file drawer problem and tolerance for null results. Psychological Bulletin, 86(3), 638-641. https://doi.org/10.1037/0033-2909.86.3.638 
Rozeboom, W. W. (1960). The fallacy of the null-hypothesis significance test. Psychological Bulletin, 57(5), 416-428. https://doi.org/10.1037/h0042040

Sena, E. S., Worp, H. B. van der, Bath, P. M. W., Howells, D. W., \& Macleod, M. R. (2010). Publication Bias in Reports of Animal Stroke Studies Leads to Major Overstatement of Efficacy. PLOS Biology, 8(3), e1000344. https://doi.org/10.1371/journal.pbio.1000344

Shettleworth, S. J. (2009). The evolution of comparative cognition: Is the snark still a boojum? Behavioural Processes, 80(3), 210-217. https://doi.org/10.1016/j.beproc.2008.09.001

Silberzahn, R., Uhlmann, E. L., Martin, D. P., Anselmi, P., Aust, F., Awtrey, E., ... Nosek, B. A. (2017). Many analysts, one dataset: Making transparent how variations in analytical choices affect results. Advances in Methods and Practices in Psychological Science. Retrieved from http://eprints.nottingham.ac.uk/48166/

Silva, F. J., Page, D. M., \& Silva, K. M. (2005). Methodological-conceptual problems in the study of chimpanzees' folk physics: How studies with adult humans can help. Animal Learning \& Behavior, 33(1), 47-58. https://doi.org/10.3758/BF03196049

Silva, F. J., Ten Hope, M. I., \& Tucker, A. L. (2014). Adult humans' understanding of support relations: An up-linkage replication. Learning \& Behavior, 42(4), 337-347. https://doi.org/10.3758/s13420-014-0151-0

Simmons, J. P., Nelson, L. D., \& Simonsohn, U. (2011). False-Positive Psychology. Psychological Science, 22(11), 1359-1366. https://doi.org/10.1177/0956797611417632

Smaldino, P. E. (2016). Not even wrong: Imprecision perpetuates the illusion of understanding at the cost of actual understanding. Behavioral and Brain Sciences, 39, e163. https://doi.org/10.1017/S0140525X1500151X

Smaldino, P. E. (2017). Models Are Stupid, and We Need More of Them. In R. R. Vallacher, S. J. Read, \& A. Nowak (Eds.), Computational Social Psychology (1st ed., pp. 311-331). https://doi.org/10.4324/9781315173726-14 
Smaldino, P. E., \& McElreath, R. (2016). The natural selection of bad science. Royal Society Open Science, 3(9), 160384. https://doi.org/10.1098/rsos.160384

Smith, P. L., \& Little, D. R. (2018). Small is beautiful: In defense of the small-N design. Psychonomic Bulletin \& Review, 25(6), 2083-2101. https://doi.org/10.3758/s13423-018-1451-8

Spiegelhalter, D. (2019). The art of statistics: How to learn from data. New York: Basic Books, an imprint of Perseus Books, a subsidiary of Hachette Book Group.

Steegen, S., Tuerlinckx, F., Gelman, A., \& Vanpaemel, W. (2016). Increasing Transparency Through a Multiverse Analysis. Perspectives on Psychological Science: A Journal of the Association for Psychological Science, 11(5), 702-712. https://doi.org/10.1177/1745691616658637

Stevens, J. R. (2017). Replicability and Reproducibility in Comparative Psychology. Frontiers in Psychology, 8, 862. https://doi.org/10.3389/fpsyg.2017.00862

Świątkowski, W., \& Dompnier, B. (2017). Replicability Crisis in Social Psychology: Looking at the Past to Find New Pathways for the Future. International Review of Social Psychology, 30(1), 111. https://doi.org/10.5334/irsp.66

Vaart, E. van der, Verbrugge, R., \& Hemelrijk, C. K. (2012). Corvid Re-Caching without 'Theory of Mind': A Model. PLOS ONE, 7(3), e32904. https://doi.org/10.1371/journal.pone.0032904 Vonk, J. (2016). Advances in Animal Cognition. Behavioral Sciences, 6(4). https://doi.org/10.3390/bs6040027

Wason, P. C. (1960). On the Failure to Eliminate Hypotheses in a Conceptual Task. Quarterly Journal of Experimental Psychology, 12(3), 129-140. https://doi.org/10.1080/17470216008416717

Wason, P. C. (1968). Reasoning about a Rule. Quarterly Journal of Experimental Psychology, 20(3), 273-281. https://doi.org/10.1080/14640746808400161

Zwaan, R. A., Pecher, D., Paolacci, G., Bouwmeester, S., Verkoeijen, P., Dijkstra, K., \& Zeelenberg, R. (2018). Participant Nonnaiveté and the reproducibility of cognitive psychology. Psychonomic Bulletin \& Review, 25(5), 1968-1972. https://doi.org/10.3758/s13423-017-1348-y 